\title{
(2) OPEN ACCESS \\ Public knowledge, preferences and experiences about medical substitute decision-making: a national cross-sectional survey
}

\section{Marcus Sellars (1) , ${ }^{1,2}$ Julien Tran, ${ }^{2}$ Linda Nolte, ${ }^{2}$ Ben White (i) , ${ }^{3}$ Craig Sinclair, ${ }^{4,5,6}$ Deirdre Fetherstonhaugh, ${ }^{7}$ Karen Detering ${ }^{2,8}$}

\begin{abstract}
- Additional material is published online only. To view please visit the journal online (http://dx.doi.org/10.1136/ bmjspcare-2020-002619)
\end{abstract}

For numbered affiliations see end of article.

\section{Correspondence to}

Dr Marcus Sellars, Department of Health Services Research \& Policy, Research School of Population Health, College of Health \& Medicine, The Australian National University, Canberra, Australian Capital Territory, Australia; marcus.sellars@anu.edu.au

Received 3 August 2020 Revised 1 February 2021 Accepted 12 February 2021

\section{Check for updates}

(c) Author(s) (or their employer(s)) 2021. Re-use permitted under CC BY-NC. No commercial re-use. See rights and permissions. Published by BMJ.

To cite: Sellars M, Tran J, Nolte L, et al. BMJ Supportive \& Palliative Care Epub ahead of print: [please include Day Month Year]. doi:10.1136/ bmjspcare-2020-002619

\section{ABSTRACT}

Objective To describe the Australian adult public's knowledge and experiences regarding substitute decision-making for medical decisions and their preferences for obtaining information about the substitute decisionmaker (SDM) role.

Methods This is a national cross-sectional online survey of the Australian adult public. The survey examined participants' advance care planning (ACP) awareness and experience, SDM experiences and preferences for obtaining more information about SDM, and participant knowledge about SDM.

Results Of 1586 people who opened the survey, $1120(70.6 \%)$ were included in the final sample. $13 \%(n=142)$ of participants indicated they had acted as an SDM. A median score of two correct responses out of five showed low to moderate knowledge about the SDM role among all participants, with only 33\% reporting awareness of SDM laws existing in Australia. While most (59\%) participants ranked a health professional as their preferred source of obtaining information about supporting SDMs, few participants who had been an SDM ( $n=64,45 \%)$ reported obtaining any support in making medical decisions. The median SDM knowledge scores for people who had discussed ACP (3.0 vs 2.0, $U=145222$, $z=6.910, p<0.001)$, documented their ACP preferences (3.0 vs 2.0, $U=71984, z=4.087$, $\mathrm{p}<0.001$ ) or acted in the SDM role (3.0 vs 2.0, $U=56353, z=-3.694, p<0.001$ ) were significantly higher compared with those who had not.

Conclusions The Australian public may have low to moderate knowledge about the SDM role and access only minimal support when making challenging medical decisions.

\section{Key messages}

What was already known?

- A healthcare substitute decision-maker (SDM) is a person who has legal power to make medical decisions on another's behalf if they are unable to make these decisions for themselves.

- The role of SDMs for medical decisions is very significant as decisions about healthcare can include consenting to, withholding and/or withdrawing lifesustaining treatment.

What are the new findings?

- Few (13\%) members of the Australian adult public had acted in the SDM role, and low to moderate knowledge about the SDM role was observed overall, with only $33 \%$ of participants reporting knowledge that SDM laws existed in Australia.

- Of those who had acted in the SDM role, challenges about knowing the best decision to make and making decisions about end of life were the most frequently reported, but only a minority of participants indicated they had obtained any support in the SDM role.

What is their significance?

- The Australian community's ability to appoint an SDM, and for the SDM to act appropriately, depends on awareness of the requirements of these roles, however, the low to moderate knowledge of the SDM role observed in this study suggests this may be problematic.

- The findings also indicate a potential need to develop resources addressing the types of challenges SDMs are likely to encounter, and for this content be delivered in ways that are preferable for potential SDMs.

\section{INTRODUCTION}

In high-income Western countries, there has been increasing recognition that 
end-of-life care is suboptimal. ${ }^{12}$ Simultaneously, there has been greater emphasis on autonomy (the right to make one's own decisions) ${ }^{3-5}$ and informed consent in the ethical and legal discourse, ${ }^{6}$ representing a shift away from medical paternalism in healthcare delivery. ${ }^{7}$ One of the main issues identified is that preferences about end-of-life care for people (including those at high risk of dying) are often unknown. This often leaves substitute decision-makers (SDMs) to make difficult end-of-life decisions on the person's behalf ${ }^{8}$ and tends to result in more intensive treatments than the person would have otherwise wanted. ${ }^{9}$

In general, a healthcare SDM refers to a person who has legal power to make medical decisions on another's behalf if they are unable to make these decisions for themselves. ${ }^{10}$ Laws which facilitate medical decision-making by SDMs are common internationally, including, for example, in North America, ${ }^{11}$ Europe $^{12}$ and the Asia Pacific region. ${ }^{13}$ However, the terminology and legal standing of SDMs vary depending on local legislation (eg, surrogate or proxy decisionmaker). In Australia, SDMs can be nominated by the person within an advance care directive, appointed by a tribunal or assigned by laws that make provisions for a hierarchy of persons who would undertake this role when no one has been appointed. ${ }^{14}$ The role of SDMs in medical decisions is very significant as decisions about healthcare could include consenting to, withholding and/or withdrawing life-sustaining treatment. ${ }^{15}$

In addition to the existence of legislative frameworks relating to SDMs, interventions such as advance care planning (ACP) ${ }^{816}$ can educate and prepare SDMs and help to clarify the person's goals and values to inform future decision-making. ${ }^{17}$ Yet, despite potential benefits, uptake of ACP is low in Australia ${ }^{18-20}$ and internationally ${ }^{21}$ and the role of SDM remains a challenging experience. ${ }^{2-25}$ Difficulties can arise when the SDM's values do not align with the preferences of the person for whom they are making decisions, ${ }^{232627}$ if there is disagreement between the SDM and health professionals, ${ }^{17}$ or other family members or supporters, ${ }^{23}$ or when the SDM feels uncertain making decisions that best reflect the preferences and values of the person. ${ }^{28}$ This uncertainty is further demonstrated in studies that show only modest rates of concordance between endof-life decisions made by SDMs and the preferences of the person for whom they are making decisions. ${ }^{29}$

Few studies have attempted to describe the general public's knowledge, preferences and experiences regarding the SDM role. A 2016 Australian study involving participants from the three most populous Australian states examined community awareness and knowledge of the laws relating to end-of-life care. ${ }^{30}$ This showed that although 19\% had experience of making end-of-life decisions for others and 12\% had formally appointed an SDM, almost half of the sample lacked required knowledge regarding SDM legislation. In addition, a recent national survey of Canadians examining preparedness to act as an SDM showed that while $25 \%$ of the sample had previous experience as an SDM and $71 \%$ believed they would have to act as an SDM in the future, $62 \%$ believed they understood the SDM role and only 53\% felt prepared to be an SDM. ${ }^{31}$

The authors are not aware of additional similar studies exploring the general public's knowledge and preparedness for the SDM role. However, observational studies from the USA suggest being an SDM is associated with elevated levels of anxiety and depression in some people ${ }^{32}$ and that a person's confidence to be an SDM varies substantially, with people who have previous SDM experience or greater communication with the patient's doctor demonstrating increased confidence levels compared with those who do not. ${ }^{33}$ Yet it may not be common for health professionals to provide guidance to SDMs in practice, such as counselling an SDM on how to perform the role or the principles underpinning it, suggesting a need to understand the specific challenges SDMs experience and their preferences for obtaining support in the role. ${ }^{34}$

Little is known about the Australian public's knowledge about the SDM role (such as how to access information and support, and other legal rights) or how common it is to have acted in the SDM role, the types of medical decisions that SDMs make and the support SDMs access to make such decisions. This study aims to address this gap and to describe the Australian adult public's knowledge and experiences regarding substitute decision-making for medical decisions and their preferences for obtaining more information about the SDM role.

\section{METHODS}

Study reporting is based on the Strengthening the Reporting of Observational Studies in Epidemiology statement: guidelines for reporting observational studies. $^{35}$

In September 2018, a cross-sectional online survey was conducted nationally over 9 days.

\section{Survey development}

The survey was developed following a literature review and research team discussion, and then further refined following a pilot with 14 adult Australians to assess question comprehension. The survey comprised five sections (online supplemental file 1). Demographic information collected was adapted from the categories used by the Australian Bureau of Statistics. ${ }^{36}$ To determine ACP awareness and experience, participants were asked if they knew about ways to plan for future medical care (yes/no), were then presented with a definition of ACP adapted from the international literature $^{16}$ (see online supplemental file 1) and then asked if they had heard of ACP prior to the survey. Participants were asked if they knew about ways to plan for future medical care and what types of ACP 


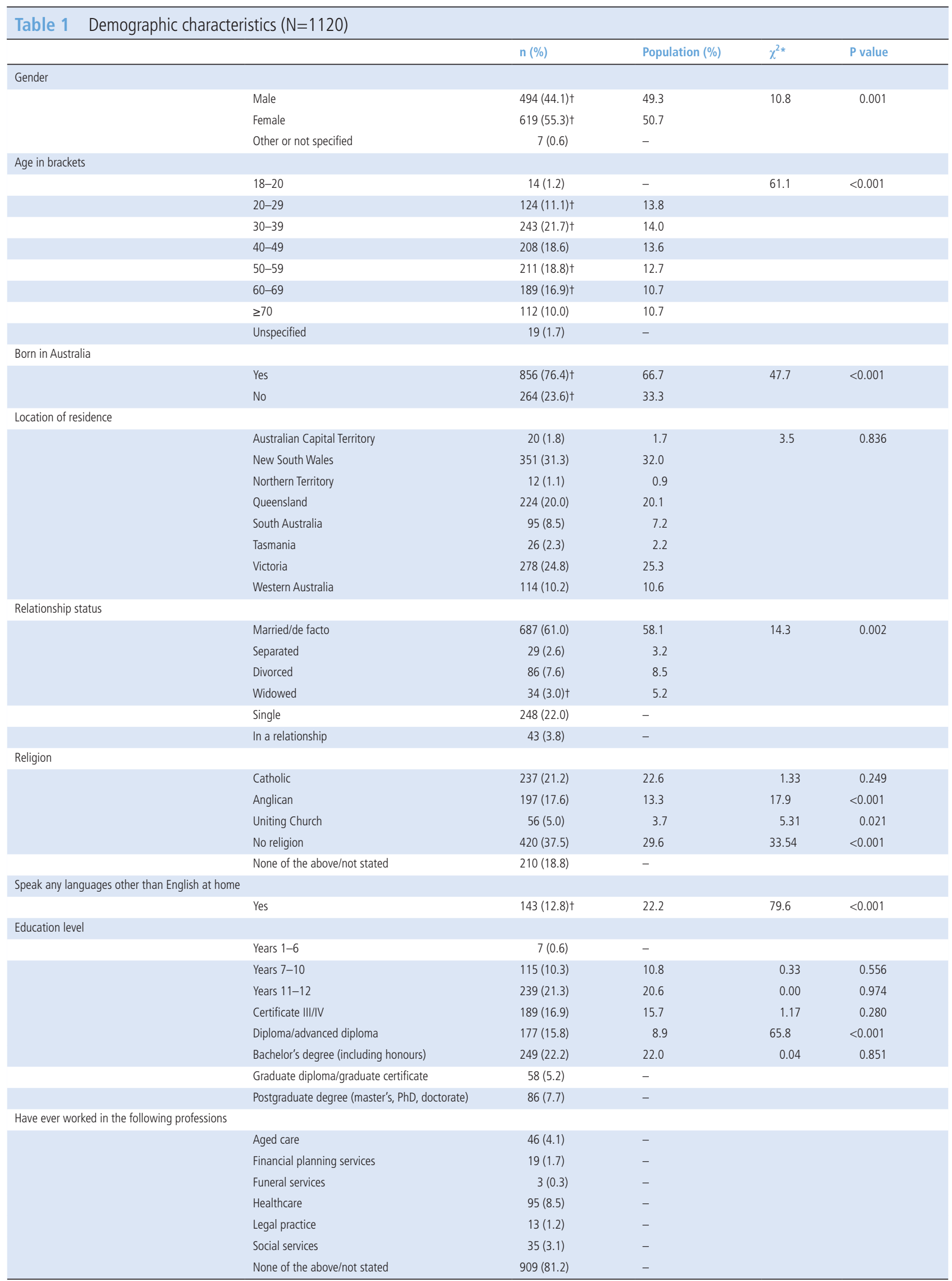

*Variables with no population value (eg, gender, other or not specified) excluded from the analysis.

tIndicates large contribution to the overall test statistics. 
experiences they had had (if any). Types of ACP experiences included any previous discussions with others about ACP, outcomes after ACP discussions (such as ACP documentation, including appointment of an SDM) and whether they had ever been involved in a discussion with their family, friends or other people about their preferences regarding ACP.

Participants were also presented with a definition of an SDM for medical decisions (see online supplemental file 1) and asked if they had ever made medical decisions on behalf of someone else after being appointed by them as an SDM (yes/no). They were then asked to rank their most to least preferred source of obtaining information about how to support SDMs make their decisions from six options (an event, discussion with a family member or friend, traditional media, new media, healthcare professional or other). If participants had previously been an SDM, they were asked what types of decisions they had made, the most challenging aspects about making those decisions and the type of support accessed that helped them with their decisions (if any). Participants' SDM knowledge was assessed using five questions (three about accessing information and support or consulting with others in the SDM role, one about SDM laws and one about resigning from an SDM appointment) to be answered 'True', 'False' or 'Don't know'.

\section{Sampling}

Adults who had voluntarily signed up to a recruitment agency register (Dynata; https://www.dynata.com/) were invited to complete the survey through invitations and advertisements on the company's website. At the time of the survey, the estimated number of registrants on the company's Australian panel was 1000000 and participants were reimbursed for the inconvenience (ie, time taken) to complete the survey, as set out and provided by the recruitment agency. Participants were eligible if they were aged 18 years or older and residing in Australia at the time of the study. Participation was voluntary and all responses were anonymous. Participants were informed that consent was implied by completing the survey.

In addition, with the aim of achieving a nationally representative sample, quotas were set for gender and state or territory based on the 2016 Australian census data. ${ }^{36}$ This resulted in men and people from the Northern Territory being invited to participate in a second round of invitations, as responses were initially low in these groups. Given the use of non-probabilistic sampling (ie, opt-in), we were unable to estimate a response rate in accordance with standardised definitions. ${ }^{37}$ Participants were included in the final sample if they had completed sufficient questions to address the research questions (up to question 27; having been appointed an SDM and made medical decisions in that role). ${ }^{38}$ The survey took approximately $15-30 \mathrm{~min}$ to complete.

\section{Data analysis}

Incomplete responses $(n=59)$ were excluded from the analysis. Variable recoding and data analyses were conducted in SPSS V.23.0. Initial descriptive analyses tabulated experience with ACP and substitute decision-making and preferences and knowledge about the SDM role. Sample representativeness was assessed by comparing demographics (age, gender, location of birth, location of residence, relationship status and speaks languages other than English) with population census data. Mann-Whitney U tests and Kruskal-Wallis $\mathrm{H}$ tests were run to determine whether there were any differences between the total number of SDM knowledge questions answered correctly and having had experience with ACP, substitute decision-making or working in a relevant profession ('aged care', 'financial planning services', 'funeral services', 'healthcare', 'legal practice', 'social services' or 'none of the above'). In addition, to determine whether there were differences between levels of working in a relevant profession and SDM knowledge, pairwise comparisons were performed using Dunn's ${ }^{39}$ procedure with a Bonferroni correction for multiple comparisons (statistical significance accepted at the $\mathrm{p}<0.0023$ level). Alpha levels for statistical significance were set at $\mathrm{p}<0.05$ for all other analyses.

Content analysis ${ }^{40}$ was undertaken to describe responses to questions about SDM experiences: types of decisions made, most challenging aspects about making those decisions and type of support accessed that helped them with their decisions (if any). Codes were initially drafted by MS inductively based on each free-text response and a coding framework was developed, which was revised through discussion and consensus within the research team. Coding was undertaken (each response dichotomously coded (yes/ no) to confirm the presence of a code) by two independent coders trained in qualitative research (MS and JT). Following this and using SPSS V.23.0, intercoder reliability was assessed using Cohen's kappa, showing a substantial to almost perfect agreement for all codes (all kappas $>0.743$ ). Discrepancies were resolved by discussion among coders.

\section{RESULTS}

In total, of 1586 people who opened the survey, 1000 completed all survey questions. Two were screened out because they did not meet the eligibility criteria and 409 were redirected from the survey because sampling quotas had been exceeded. Of the 175 partial completers, 120 were included in the final sample $(\mathrm{N}=1120$; completion rate $70.6 \%)$.

The characteristics of the sample compared with the 2016 population census data are shown in table 1 . Participant characteristics were comparable with population census statistics in terms of location of residence and most categories relating to relationship status, religion and education level. However, participants were 
Table 2 Awareness and experience regarding ACP $(\mathrm{N}=1120)$

$\mathrm{n}(\%)$

\begin{tabular}{|c|c|}
\hline $\begin{array}{l}\text { Do you know about ways you can plan for your future } \\
\text { medical care and what would happen if you could not make } \\
\text { decisions or speak for yourself? }\end{array}$ & \\
\hline Yes & $611(54.6)$ \\
\hline No & $509(45.4)$ \\
\hline Had heard about ACP prior to the survey & \\
\hline Yes & $431(38.5)$ \\
\hline No & $689(61.5)$ \\
\hline Source of learning or hearing about ACP $(n=431)$ & \\
\hline Healthcare professional (eg, nurse, general practitioner) & $173(40.1)$ \\
\hline Family or friends & $262(60.8)$ \\
\hline $\begin{array}{l}\text { Traditional media (television, radio, newspaper, magazines, } \\
\text { flyers/brochures/booklets, signs/billboards) }\end{array}$ & $128(29.7)$ \\
\hline $\begin{array}{l}\text { New media (social media, eg, Facebook and Twitter, website, } \\
\text { and smartphone apps) }\end{array}$ & $74(17.2)$ \\
\hline Legal practitioner & $70(16.2)$ \\
\hline Financial planner & $31(7.2)$ \\
\hline An event & $20(4.6)$ \\
\hline Other & $94(21.8)$ \\
\hline
\end{tabular}

If knew about ways to plan for future medical care, ever had a discussion about $A C P(n=611)$

Yes

No

Discussed ACP with $(n=267)$

Your family

Friends

$267(43.7)$

$344(56.3)$

Health professionals

$211(79.0)$

Legal practitioner

$64(24.0)$

$75(28.1)$

$42(15.7)$

Other/unclear (eg, financial advisor/planner)

$6(2.2)$

Outcome(s) after the ACP discussion ( $n=267$ )

Told my family, friends or doctor about medical treatments I 163 (61.0) would or would not want if I could no longer tell them

Completed a document outlining my future medical $\quad 82$ (30.7)

treatment and care preferences in writing

Completed a form appointing someone to make medical

decisions on my behalf in case I could no longer tell them in

the future

Completed at least one type of ACP documentation listed

above (either to document their future treatment preferences or to appoint an SDM)

Decided not to complete advance care planning

Other

$31(11.6)$

$15(5.6)$

Ever been involved in a discussion with your family, friends or other people about their preferences regarding advance care planning (only asked if previously had a discussion about $\mathrm{ACP}, \mathrm{n}=267$ )

$\begin{array}{ll}\text { Yes } & 230 \text { (85.9) }\end{array}$

No 37 (14.1)

ACP, advance care planning; SDM, substitute decision-maker.

more commonly female (55\% vs $51 \%$ ), older (median age 48 years vs 38 years), born in Australia (76\% vs $67 \%$ ) and less commonly spoke a language other than English at home (13\% vs 22\%) than the broader Australian population.

Experiences with ACP are shown in table 2. Most participants had never heard of ACP (62\%) or discussed
ACP with others (76\%). Only 10\% $(n=117)$ reported having completed ACP documentation (either to document their future treatment preferences or to appoint an SDM or both). Of those who had been involved in an ACP discussion with others $(n=267), 61 \%(n=163)$ had told someone about their future treatment preferences, and of these $30 \%(n=50)$ had also documented their ACP preferences. Of the group who had discussed ACP, a larger proportion $(86 \%, n=230)$ reported having discussed the ACP preferences of someone else as opposed to discussing their own ACP preferences.

\section{SDM experience and preferences}

Of the participants $13 \%(n=142)$ indicated they had acted in the role of SDM and made medical decisions on an adult's behalf after they were appointed by them. Table 3 shows the final coding categories, the frequency of these and examples of participant quotations to illustrate. Decisions about routine treatment and end of life were most frequently reported $(n=22$, $16 \%$ ), and 'knowing the best decision to make' and 'making decisions about end of life' were the most commonly reported challenges $(n=25,17 \%)$. Of the 142 who acted in an SDM role and made decisions for others, 64 (45\%) reported accessing support, with help from doctors being the most commonly accessed $(\mathrm{n}=30,21 \%)$.

Participants' preferred source(s) of obtaining more information to support SDMs to make their decisions were (from most to least preferred for six sources, $\mathrm{n}=1049)$ healthcare professionals $(59 \%, \mathrm{n}=621)$, discussion with a family member or friend (23\%, $\mathrm{n}=236)$, traditional media $(7 \%, \mathrm{n}=69)$, new media $(6 \%, n=61)$, an 'other source' $(3 \%, n=35)$ followed by an event $(3 \%, \mathrm{n}=27)$.

\section{Knowledge regarding SDMs}

Participants had a median correct response score of 2.00 (out of a maximum of 5) (table 4). The question least frequently answered correctly was regarding laws about SDMs $(33 \%, n=374)$, with most participants $(58 \%)$ reporting they did not know if there were laws regarding SDMs where they live (table 5). Similarly, most participants (65\%) incorrectly answered the question about SDMs being limited in their ability to consult others when making their decisions. The question most frequently answered correctly was regarding SDMs' ability to access information from healthcare providers about the person they are making decisions for $(64 \%)$.

The median knowledge scores for people who had ever discussed ACP (3.0 vs 2.0, $\mathrm{U}=145222, \mathrm{z}=6.910$, $\mathrm{p}<0.001)$, documented their ACP preferences $(3.0$ vs $2.0, \mathrm{U}=71984, \mathrm{z}=4.087, \mathrm{p}<0.001)$ or acted in the SDM role (3.0 vs 2.0, $\mathrm{U}=56353, \mathrm{z}=-3.694$, $\mathrm{p}<0.001)$ were significantly higher compared with those who had not. In addition, a Kruskal-Wallis $\mathrm{H}$ test was conducted to determine if there were differences 
Table 3 Content and example quotations for types of SDM decisions made, most challenging aspects of these decisions and support accessed to support them with their decision $(n=142)$

\begin{tabular}{|c|c|c|}
\hline Content* & Quotations & $\mathrm{n}(\%)$ \\
\hline \multicolumn{3}{|l|}{ Type of medical decisions made } \\
\hline $\begin{array}{l}\text { Routine treatment and care (eg, dentist, diet, } \\
\text { medications) }\end{array}$ & $\begin{array}{l}\text { "If that person needs dental treatment or not." } \\
\text { "Doctor, dentist." }\end{array}$ & $22(15.5)$ \\
\hline $\begin{array}{l}\text { End-of-life care decisions (eg, to withdraw or } \\
\text { continue treatment, to administer resuscitation, } \\
\text { chemotherapy, a feeding tube or antibiotics, } \\
\text { to adopt a conservative pathway, follow ACP } \\
\text { documentation) }\end{array}$ & $\begin{array}{l}\text { "To make decisions regarding end of life care and treatment." } \\
\text { "Life support." } \\
\text { "The decision to allow (my husband) to pass away in the nursing home." }\end{array}$ & $18(12.7)$ \\
\hline To continue with/decide course of treatment & $\begin{array}{l}\text { "Continuation of treatment." } \\
\text { "Course of treatment." }\end{array}$ & $9(6.3)$ \\
\hline Surgery/operations & $\begin{array}{l}\text { "Liver transplant." } \\
\text { "About the surgery they need to undergo immediately." }\end{array}$ & $8(5.6)$ \\
\hline Hospitalisation & $\begin{array}{l}\text { "About hospitalizing a family member." } \\
\text { "Deciding to take the person to hospital." }\end{array}$ & $8(5.6)$ \\
\hline $\begin{array}{l}\text { Future treatment and care in the event of a } \\
\text { deterioration }\end{array}$ & $\begin{array}{l}\text { "What to do if suffers heart attack." } \\
\text { "d n r." }\end{array}$ & $7(4.9)$ \\
\hline Transfer to aged care facility & $\begin{array}{l}\text { "Dementia putting my father into a nursing home for care." } \\
\text { "Moving into aged care facility." }\end{array}$ & $4(2.8)$ \\
\hline Acute medical problem (eg, cancer, stroke) & $\begin{array}{l}\text { "Treatment of a stroke." } \\
\text { "Ongoing cancer treatment." }\end{array}$ & $4(2.8)$ \\
\hline $\begin{array}{l}\text { Choosing a healthcare provider or medical } \\
\text { insurance }\end{array}$ & $\begin{array}{l}\text { "Buy medical insurance." } \\
\text { "Medical provider to choose one." }\end{array}$ & $3(2.1)$ \\
\hline Medical tests and assessments & "My mother had dementia. Took her to the doctor to have her assessed." & $2(1.4)$ \\
\hline Respite care & "Respite care." & $2(1.4)$ \\
\hline Not specified or unclear & & $63(44.4)$ \\
\hline \multicolumn{3}{|c|}{ The most challenging aspects of making these decisions (if any) } \\
\hline No challenges & $\begin{array}{l}\text { "None." } \\
\text { "No challenge quite straight forward." }\end{array}$ & $31(21.8)$ \\
\hline $\begin{array}{l}\text { Knowing what decision to make and making the } \\
\text { best/most correct decision (eg, is what the person } \\
\text { would have wanted, if preferences misaligned } \\
\text { with person or others, not having medical } \\
\text { knowledge) }\end{array}$ & $\begin{array}{l}\text { "Just deciding which way to go." } \\
\text { "Being certain that the person really agreed with DNR." }\end{array}$ & $25(17.6)$ \\
\hline Decision about end of life & $\begin{array}{l}\text { "Having a parent who chose no treatment and preferred to die in pain." } \\
\text { "Knowing that she would die." }\end{array}$ & $9(6.3)$ \\
\hline Family & $\begin{array}{l}\text { "Waiting for the rest of family." } \\
\text { "Siblings." }\end{array}$ & $6(4.2)$ \\
\hline Impact on others, helping others & $\begin{array}{l}\text { "Impact on others." } \\
\text { "Helping people." }\end{array}$ & $5(3.5)$ \\
\hline Emotions & $\begin{array}{l}\text { "Grief." } \\
\text { "The burden of guilt even though I was sure I was meeting their wishes." }\end{array}$ & $4(2.8)$ \\
\hline Financial issues & $\begin{array}{l}\text { "Money effect." } \\
\text { "Financial crisis." }\end{array}$ & $4(2.8)$ \\
\hline Government/paperwork & $\begin{array}{l}\text { "Government." } \\
\text { "Dealing with bureaucrats." }\end{array}$ & $3(2.1)$ \\
\hline Own health & "My health." & $3(2.1)$ \\
\hline Being responsible for someone else & "Taking responsibility for someone else." & $2(1.4)$ \\
\hline Struggling to help the person & $\begin{array}{l}\text { "Watching her getting more and more frustrated at being denied the right to a } \\
\text { dignified death at a time of her own choosing." } \\
\text { "Trying to keep my Friend comfortable and pain free." }\end{array}$ & $2(1.4)$ \\
\hline Not specified or unclear & & $44(31.0)$ \\
\hline \multicolumn{3}{|c|}{ Type of support (if any) accessed to help you with your decision } \\
\hline None & $\begin{array}{l}\text { "No help or support." } \\
\text { "None." }\end{array}$ & $33(23.2)$ \\
\hline Doctors (medical staff) & $\begin{array}{l}\text { "Medical professionals." } \\
\text { "Specialist doctor." }\end{array}$ & $30(21.1)$ \\
\hline Family or friends & $\begin{array}{l}\text { "Sibling." } \\
\text { "Other family members." }\end{array}$ & $22(15.5)$ \\
\hline
\end{tabular}




\begin{tabular}{|c|c|c|}
\hline Content* & Quotations & n (\%) \\
\hline $\begin{array}{l}\text { Other healthcare professionals and services (eg, } \\
\text { hospitals, palliative care, aged care assessment } \\
\text { team, social workers) }\end{array}$ & $\begin{array}{l}\text { "Pharmacist, social worker." } \\
\text { "Nursing staff." }\end{array}$ & $16(11.3)$ \\
\hline Support not needed & $\begin{array}{l}\text { "Luckily I didn't have to make that call because after } 7 \text { weeks he was allowed } \\
\text { home thank goodness." }\end{array}$ & $2(1.4)$ \\
\hline Counselling or support groups & "A support group." & $3(2.1)$ \\
\hline Internet & "Internet." & $2(1.4)$ \\
\hline Religion & "None other than prayer." & $1(0.7)$ \\
\hline Not specified or unclear & & $43(30.3)$ \\
\hline
\end{tabular}

*Multiple codes were permitted.

ACP, advance care planning; DNR, do-not-resuscitate order; SDM, substitute decision-maker.

Table 4 Associations between total knowledge questions answered correctly regarding substitute decision-making and SDM, ACP and professional experiences

\begin{tabular}{|c|c|c|c|c|c|c|c|c|c|c|}
\hline \multirow[t]{2}{*}{ Variable } & & \multicolumn{6}{|c|}{ Total correct responses, n (\%) } & \multirow[t]{2}{*}{ M } & \multirow[t]{2}{*}{$\begin{array}{l}\text { Test } \\
\text { statistics* }\end{array}$} & \multirow[t]{2}{*}{ P value } \\
\hline & & 0.00 & 1.00 & 2.00 & 3.00 & 4.00 & 5.00 & & & \\
\hline \multirow[t]{2}{*}{ Acted in SDM role } & Yes $(n=142)$ & $10(7.0)$ & $21(14.8)$ & $28(19.7)$ & $38(26.8)$ & $31(21.8)$ & $14(9.9)$ & 3.0 & 56353 & $<0.001$ \\
\hline & No $(n=978)$ & $202(20.7)$ & $152(15.5)$ & $189(19.3)$ & $204(20.9)$ & $150(15.3)$ & $81(8.3)$ & 2.0 & & \\
\hline \multirow[t]{2}{*}{ Discussed ACP } & Yes $(n=269)$ & $14(5.2)$ & $37(13.9)$ & $51(19.1)$ & $73(27.3)$ & $60(22.5)$ & $32(12.0)$ & 3.0 & 145222 & $<0.001$ \\
\hline & No $(n=851)$ & $198(23.3)$ & $136(15.9)$ & $166(19.5)$ & $169(19.8)$ & $121(14.2)$ & $63(7.4)$ & 2.0 & & \\
\hline \multirow{2}{*}{$\begin{array}{l}\text { Completed ACP } \\
\text { documentation }\end{array}$} & Yes $(n=117)$ & $5(4.3)$ & $19(16.2)$ & $20(17.1)$ & $33(28.2)$ & $29(24.8)$ & $11(9.4)$ & 3.0 & 71984 & $<0.001$ \\
\hline & No $(n=1003)$ & $207(20.6)$ & $154(15.4)$ & $197(19.6)$ & $209(20.8)$ & $152(15.2)$ & $84(8.4)$ & 2.0 & & \\
\hline \multirow{7}{*}{$\begin{array}{l}\text { Worked in any } \\
\text { of the following } \\
\text { professions (yes) }\end{array}$} & Aged care $(n=46)$ & $4(8.7)$ & $6(13.0)$ & $10(21.7)$ & $12(26.1)$ & $11(23.9)$ & $3(6.5)$ & 3.0 & 32.0 & $<0.001$ \\
\hline & $\begin{array}{l}\text { Financial planning } \\
\text { services }(n=19)\end{array}$ & $2(10.5)$ & $1(5.3)$ & $4(21.1)$ & 7 (36.8) & $4(21.1)$ & $1(5.3)$ & 3.0 & & \\
\hline & Funeral services $(n=3)$ & - & - & $1(33.3)$ & $1(33.3)$ & $1(33.3)$ & - & 3.0 & & \\
\hline & Healthcare $(n=95)$ & $10(10.5)$ & $10(10.5)$ & $23(24.2)$ & $25(26.3)$ & $20(21.1)$ & $7(7.4)$ & 3.0 & & \\
\hline & Legal practice $(n=13)$ & - & - & - & $3(23.1)$ & $5(38.5)$ & $5(38.5)$ & 4.0 & & \\
\hline & Social services $(n=35)$ & $4(11.4)$ & $8(22.9)$ & 4 (11.4) & $10(28.6)$ & $5(14.3)$ & $4(11.4)$ & 3.0 & & \\
\hline & $\begin{array}{l}\text { None of the above or } \\
\text { not specified ( } n=909 \text { ) }\end{array}$ & $192(21.1)$ & $148(16.3)$ & $175(19.3)$ & $184(20.2)$ & $135(14.9)$ & $75(8.3)$ & 2.0 & & \\
\hline Total $(\mathrm{N}=1120)$ & & $212(18.9)$ & $173(15.4)$ & $217(19.4)$ & $242(21.6)$ & $181(16.2)$ & $95(8.5)$ & 2.0 & & \\
\hline
\end{tabular}

Table 5 Knowledge about substitute decision-makers ( $\mathrm{N}=1120)$

Don't know if Answered

Believes statement Believes statement statement is true correctly, $\mathrm{n}$

is true, $\mathrm{n}(\%) \quad$ is false, $\mathrm{n}(\%) \quad$ or false, $\mathrm{n}(\%) \quad(\%)$

\begin{tabular}{|c|c|c|c|c|}
\hline $\begin{array}{l}\text { To help them to make their decisions, substitute decision-makers } \\
\text { can access all information about the person they are making } \\
\text { decisions for from healthcare provider(s) - True. }\end{array}$ & $721(64.4)$ & $83(7.4)$ & $316(28.2)$ & 721 (64.4) \\
\hline $\begin{array}{l}\text { Substitute decision-makers cannot seek a second opinion from } \\
\text { other healthcare providers to help inform them when making } \\
\text { decisions on someone's behalf-False. }\end{array}$ & $188(16.8)$ & $552(49.3)$ & $380(33.9)$ & 552 (49.3) \\
\hline $\begin{array}{l}\text { Where I live, there are no laws about substitute decision- } \\
\text { makers-False. }\end{array}$ & $97(8.7)$ & $374(33.2)$ & 649 (57.9) & $374(33.2)$ \\
\hline $\begin{array}{l}\text { Substitute decision-makers are limited in who they can consult in } \\
\text { helping them make their decisions-False. }\end{array}$ & $235(21.0)$ & $392(35.0)$ & $493(44.0)$ & $392(35.0)$ \\
\hline $\begin{array}{l}\text { Once a person has been legally appointed as a substitute } \\
\text { decision-maker, they cannot resign from that appointment-False. }\end{array}$ & 152 (13.6) & $493(44.0)$ & $475(42.4)$ & $493(44.0)$ \\
\hline
\end{tabular}


in knowledge scores between people who differed in relevant professional experience: aged care $(n=46)$, financial planning services $(n=19)$, funeral services $(n=3)$, healthcare $(n=95)$, legal practice $(n=13)$, social services $(n=35)$ or none of the above $(n=909)$. Distributions of knowledge scores were not similar for all groups, as assessed by visual inspection of a boxplot, with legal practices group appearing to have greater frequency of higher scores. The distributions of knowledge scores were statistically significantly different between participant groups with relevant professional experience $\left(\chi^{2}(6)=32.032, p<0.001\right)$. A post-hoc analysis showed statistically significant differences in knowledge scores between people who had ever worked in legal practice (mean rank $=939.27$ ) and healthcare (mean rank $=628.58)(\mathrm{p}=0.020)$, legal practice and social services (mean rank $=599.89$ ) $(\mathrm{p}=0.021)$, and legal practice and people who had not worked in any of the professions or did not specify a response (mean rank $=540.13)(\mathrm{p}<0.001)$. Statistical significance was not identified in any other group combination.

\section{DISCUSSION}

This study describes the Australian adult public's knowledge and experiences regarding substitute decision-making for medical decisions and their preferences for obtaining more information about the SDM role. Less than four in ten participants reported that they had heard of, or discussed, ACP and only $11 \%$ reported having documented their ACP preferences. Similarly, few (13\%) participants had acted in the SDM role and the median score of two correct responses out of five in all participants indicates low to moderate knowledge about the SDM role. It is striking that only $33 \%$ of participants reported knowing that SDM laws existed in Australia. Of those who had acted in the SDM role, challenges about knowing the best decision to make and making decisions about end of life were the most frequently reported. In addition, while most ranked a health professional as their preferred source of obtaining information about how to support SDMs in their role, few participants indicated they had obtained any support in the SDM role.

The Australian community's ability to appoint an SDM, and for the SDM to act appropriately, depends on awareness of the requirements of these roles. It is likely that SDMs would be more likely to advocate on behalf of the person regarding treatment preferences or use legal recourse (such as a tribunal) if they are aware of existing legislation that will support them in this process. ${ }^{41}$ However, this study found low awareness of ACP, limited engagement with ACP behaviours (such as discussing or documenting medical treatment preferences) and low to moderate SDM knowledge in the sample overall, suggesting these may be problematic. Nonetheless, participants in our study with ACP or SDM experience answered significantly more SDM knowledge questions correctly than those without these experiences, which suggests participating in such activities may improve a person's knowledge regarding the SDM role and the laws that underpin it. This may be a result of experiences associated with acting in the SDM role, the professional support accessed by some who reported this, or alternatively they might have been selected into the role (or self-selected to some extent) due to greater health/legal literacy.

Past studies show SDMs can experience stress and uncertainty if they feel insufficient information has been provided to support them in their role. ${ }^{42}{ }^{43}$ In our study, some people who had acted in the SDM role also encountered challenges in knowing the best decision to make and making decisions about end of life. However, few participants reported accessing support to help them make these decisions, which highlights a potential need to develop resources addressing the types of challenges SDMs are likely to encounter and for this content to be delivered in ways that are preferable for potential SDMs. Findings from a recent survey among the Canadian general population showed that most participants would support the introduction of a curriculum for senior high school students to learn about being an SDM,${ }^{31}$ further highlighting the need to develop and evaluate interventions that address the problem of a lack of preparedness to be an SDM in the general public. ${ }^{44}$

In our study, a majority of participants preferred to obtain information from a health professional. This is consistent with a recent Australian study which found most people preferred to learn about end-oflife law from health professionals. ${ }^{30}$ This highlights the importance of doctors, nurses and others involved in a person's care being well informed about relevant legislation and confident to educate and counsel SDMs regarding their role.

One challenge, however, is that the law in this field is complex and past studies of Australian doctors show significant knowledge gaps in end-of-life $\mathrm{law}^{45}$ and varying attitudes towards its helpfulness in clinical practice. ${ }^{46}$ Accordingly, participants who had worked in healthcare showed no evidence of increased SDM knowledge compared with participants without such professional experience. The small sample of participants who had worked in legal practice were the only group who answered significantly more SDM knowledge questions correctly than those without relevant professional experience. This suggests that education for health professionals may improve their ability to support SDMs to make medical decisions.

\section{Strengths and limitations}

To our knowledge, this is the first national study to examine the Australian public's knowledge about SDM role or how common it is to have acted in the SDM role, the types of medical decisions that SDMs make and the support SDMs access to make such decisions. 
All survey content was piloted for comprehensibility with people from the Australian population, and questions regarding SDMs and ACP were accompanied with definitions adapted from internationally accepted definitions where necessary. Unduly technical terms were avoided in the survey where possible. In addition, all Australian states and territories were represented, and participants' locations of residence were comparable with the broader Australian population. However, our study has some limitations that suggest caution. First, women more commonly responded to the survey than men and participants were older than the available estimates for the Australian public overall. In addition, given our opt-in sampling methodology, the generalisability of the findings to the Australian general public may be limited. However, this study was largely descriptive, and future research could employ other methodologies to achieve population representative samples values for Australian's SDM knowledge and experiences. Nonetheless, our findings regarding reported ACP documentation completion rate $(10 \%)$ were broadly comparable with those identified in a past Australian national telephone survey study conducted in $2014,{ }^{19}$ where only $14 \%$ of the sample had completed ACP documentation (advance directive).

One further challenge is the need to draft survey questions that are both legally precise across eight Australian jurisdictions and expressed in non-legal language appropriate for respondents. While legal questions were asked in accordance with Australian law, a study limitation is that, to ensure questions were understandable to the members of the community, questions were sometimes framed in terms of general principles that avoid undue legal complexity or detail that would impede comprehension. Further, the question about access to information was framed in overly broad terms as generally not all information can be obtained from healthcare providers but rather this is usually limited to that which is needed to undertake the SDM role.

\section{CONCLUSION}

This study surveyed the Australian adult public to describe their knowledge and experiences regarding substitute decision-making for medical decisions and their preferences for obtaining more information about the SDM role. The findings suggest the Australian public have low to moderate knowledge about the SDM role. In particular, there is a gap between the support required to act in the SDM role and the limited support currently available and used by SDMs. Given health professionals were identified as the preferred source of obtaining information about SDM, this suggests improved education and awareness of this cohort may indirectly support those acting as SDMs.

\footnotetext{
Author affiliations

'Department of Health Services Research \& Policy, The Australian National University, Canberra, Australian Capital Territory, Australia

${ }^{2}$ Advance Care Planning Australia, Austin Health, Melbourne, Victoria, Australia
}

${ }^{3}$ Australian Centre for Health Law Research, Queensland University of Technology, Brisbane, Queensland, Australia

${ }^{4}$ Australian Research Council Centre of Excellence in Population Ageing Research, University of New South Wales, Sydney, New South Wales, Australia

${ }^{5}$ Neuroscience Research Australia (NeuRA), Sydney, New South Wales, Australia ${ }^{6}$ School of Psychology, University of New South Wales, Sydney, New South Wales, Australia

${ }^{7}$ Australian Centre for Evidence Based Aged Care, La Trobe University, Melbourne, Victoria, Australia

${ }^{8}$ Faculty of Health, Arts and Innovation, Swinburne University, Melbourne, Victoria, Australia

Acknowledgements The authors thank Dr Sandy Clarke-Errey (University of Melbourne) for statistical consulting services.

Contributors MS formulated the study, conducted the analysis and drafted the manuscript. JT coordinated data collection, double-coded free-text responses and reviewed draft versions of the manuscript. LN, BW, CS, DF and KD provided input into the conception, design, interpretation and review of manuscript.

Competing interests None declared.

Patient consent for publication Not required.

Ethics approval The study received approval from the Austin Health Human Research Ethics Committee (reference number: HREC/43495/Austin-2018).

Provenance and peer review Not commissioned; externally peer reviewed.

Data availability statement No data are available. All data and materials relating to this research are from Austin Health and are archived and maintained according to organisational and ethical regulations. Data are not publicly available as consent was not requested for this purpose. Reasonable requests for further information relating to data can be made to the corresponding author.

Open access This is an open access article distributed in accordance with the Creative Commons Attribution Non Commercial (CC BY-NC 4.0) license, which permits others to distribute, remix, adapt, build upon this work noncommercially, and license their derivative works on different terms, provided the original work is properly cited, appropriate credit is given, any changes made indicated, and the use is noncommercial. See: http://creativecommons.org/licenses/by-nc/4. $0 /$.

ORCID iDs

Marcus Sellars http://orcid.org/0000-0002-8299-0313

Ben White http://orcid.org/0000-0003-3365-939X

\section{REFERENCES}

1 GBD 2016 Stroke Collaborators. Global, regional, and national burden of stroke, 1990-2016: a systematic analysis for the global burden of disease study 2016. Lancet Neurol 2019;18:439-58.

2 Wolf SM, Berlinger N, Jennings B. Forty years of work on endof-life care--from patients' rights to systemic reform. $N$ Engl J Med 2015;372:678-82.

3 Singer PA, Martin DK, Kelner M. Quality end-of-life care: patients' perspectives. JAMA 1999;281:163-8.

4 Rietjens JAC, van der Heide A, Onwuteaka-Philipsen BD, et al. Preferences of the Dutch General public for a good death and associations with attitudes towards end-of-life decision-making. Palliat Med 2006;20:685-92.

5 Teno JM, Casey VA, Welch LC, et al. Patient-Focused, familycentered end-of-life medical care: views of the guidelines and bereaved family members. J Pain Symptom Manage 2001;22:738-51.

6 Parker M, Stewart C, Willmott L, et al. Two steps forward, one step back: advance care planning, Australian regulatory 
frameworks and the Australian medical association. Intern Med J 2007;37:637-43.

7 Taylor K. Paternalism, participation and partnership - the evolution of patient centeredness in the consultation. Patient Educ Couns 2009;74:150-5.

8 Silveira MJ, Kim SYH, Langa KM. Advance directives and outcomes of surrogate decision making before death. $\mathrm{N} \mathrm{Engl} \mathrm{J}$ Med 2010;362:1211-8.

9 Teno JM, Fisher ES, Hamel MB, et al. Medical care inconsistent with patients' treatment goals: association with 1-year Medicare resource use and survival. J Am Geriatr Soc 2002;50:496-500.

10 Commonwealth of Australia. Royal Commission into aged care quality and safety. advance care planning in Australia, 2019. Available: https://agedcare.royalcommission.gov.au/sites/ default/files/2019-12/background-paper-5.pdf [Accessed Aug 2020].

11 Meisel A, Cerminara KL, Pope TM. The right to die: the law of end-of-life decision making. Aspen Publishers Online, 2020.

12 DeMartino ES, Dudzinski DM, Doyle CK, et al. Who Decides When a Patient Can't? Statutes on Alternate Decision Makers. N Engl J Med 2017;376:1478-82.

13 Willmott L, White B, Stackpoole C, et al. Guardianship and health decisions in China and Australia: a comparative analysis. Asian Journal of Comparative Law 2017;12:371-400.

14 Advance Care Planning Australia. Australian advance care planning laws: can we improve consistency?2019. Available: https://www.advancecareplanning.org.au/docs/default-source/ acpa-resource-library/acpa-publications/report-australian-acplaws-270520.pdf [Accessed Aug 2020].

15 Willmott L, White B, Then S-N. Withholding and withdrawing life-sustaining medical treatment. In: White B, McDonald F, Willmott L, eds. 3rd edn. Australia: Thomson Reuters (Lawbook Co.), 2018: 571-623.

16 Sudore RL, Lum HD, You JJ, et al. Defining advance care planning for adults: a consensus definition from a multidisciplinary Delphi panel. J Pain Symptom Manage 2017;53:821-32.

17 Meeker MA, Jezewski MA. Family decision making at end of life. Palliat Support Care 2005;3:131-42.

18 Detering KM, Buck K, Ruseckaite R, et al. Prevalence and correlates of advance care directives among older Australians accessing health and residential aged care services: multicentre audit study. BMJ Open 2019;9:e025255.

19 White B, Tilse C, Wilson J, et al. Prevalence and predictors of advance directives in Australia. Intern Med J 2014;44:975-80.

20 White BP, Willmott L, Tilse C, et al. Prevalence of advance care directives in the community: a telephone survey of three Australian states. Intern Med J 2019;49:1261-7.

21 Yadav KN, Gabler NB, Cooney E, et al. Approximately one in three us adults completes any type of advance directive for end-of-life care. Health Aff 2017;36:1244-51.

22 Braun UK, Beyth RJ, Ford ME, et al. Voices of African American, Caucasian, and Hispanic surrogates on the burdens of end-of-life decision making. J Gen Intern Med 2008;23:267-74.

23 Su CT, McMahan RD, Williams BA, et al. Family matters: effects of birth order, culture, and family dynamics on surrogate decision-making. J Am Geriatr Soc 2014;62:175-82.

24 Ko E, Berkman CS. Role of children in end-of-life treatment planning among Korean American older adults. J Soc Work End Life Palliat Care 2010;6:164-84.

25 Vig EK, Starks H, Taylor JS, et al. Surviving surrogate decision-making: what helps and hampers the experience of making medical decisions for others. J Gen Intern Med 2007;22:1274-9.

26 Sellars M, Clayton JM, Morton RL, et al. An interview study of patient and caregiver perspectives on advance care planning in ESRD. Am J Kidney Dis 2018;71:216-24.
27 Fritsch J, Petronio S, Helft PR, et al. Making decisions for hospitalized older adults: ethical factors considered by family surrogates. J Clin Ethics 2013;24:125-34.

28 Sellars M, Chung O, Nolte L, et al. Perspectives of people with dementia and carers on advance care planning and end-of-life care: a systematic review and thematic synthesis of qualitative studies. Palliat Med 2019;33:274-90.

29 Bravo G, Sene M, Arcand M. Surrogate inaccuracy in predicting older adults' desire for life-sustaining interventions in the event of decisional incapacity: is it due in part to erroneous quality-of-life assessments? Int Psychogeriatr 2017;29:1061-8.

30 Tilse C, Wilson J, White B, et al. Community knowledge of law on end-of-life decision-making: an Australian telephone survey. J Law Med 2019;27:399-414.

31 Wong MKY, Jiang M, Medor MC, et al. Does the public feel prepared to be substitute decision-makers? gaps in preparedness and support for a high school curriculum: a national survey. Age Ageing 2021;50:242-7.

32 Wendlandt B, Ceppe A, Choudhury S, et al. Risk factors for post-traumatic stress disorder symptoms in surrogate decisionmakers of patients with chronic critical illness. Ann Am Thorac Soc 2018; 15:1451-8.

33 Majesko A, Hong SY, Weissfeld L, et al. Identifying family members who may struggle in the role of surrogate decision maker. Crit Care Med 2012;40:2281-6.

34 Cunningham TV, Scheunemann LP, Arnold RM, et al. How do clinicians prepare family members for the role of surrogate decision-maker? J Med Ethics 2018;44:21-6.

35 von Elm E, Altman DG, Egger M, et al. The strengthening the reporting of observational studies in epidemiology (STROBE) statement: guidelines for reporting observational studies. Ann Intern Med 2007;147:573-7.

36 Australian Bureau of Statistics. Census of Population and Housing Reflecting Australia - Stories from the Census, 2016. Available: https://www.abs.gov.au/ausstats/abs@.nsf/Lookup/ by\%20Subject/2071.0 2016 Main\%20Features Snapshot $\%$ 20of\%20Australia,\%202016 2 [Accessed Aug 2020].

37 Standard Definitions. Final dispositions of case codes and outcome rates for surveys. 9th ed. Lenexa, KS: American Association for Public Opinion Research, 2016.

38 Couper M. Web surveys: a review of issues and approaches. Public Opin Q 2000;64:464-94.

39 Dunn OJ. Multiple comparisons using RANK sums. Technometrics 1964;6:241-52.

40 Hsieh H-F, Shannon SE. Three approaches to qualitative content analysis. Qual Health Res 2005;15:1277-88.

41 Hempton C, Bhatia N. Deciding For When You Can't Decide: The Medical Treatment Planning and Decisions Act 2016 (Vic). J Bioeth Inq 2020;17:109-20.

42 Givens JL, Lopez RP, Mazor KM, et al. Sources of stress for family members of nursing home residents with advanced dementia. Alzheimer Dis Assoc Disord 2012;26:254-9.

43 Cresp SJ, Lee SF, Moss C. Substitute decision makers' experiences of making decisions at end of life for older persons with dementia: a systematic review and qualitative metasynthesis. Dementia 2020;19:1532-59.

44 Prigerson HG, Viola M, Brewin CR, et al. Enhancing \& Mobilizing the POtential for Wellness \& Emotional Resilience (EMPOWER) among Surrogate Decision-Makers of ICU Patients: study protocol for a randomized controlled trial. Trials 2019;20:408.

45 White B, Willmott L, Cartwright C, et al. Doctors' knowledge of the law on withholding and withdrawing life-sustaining medical treatment. Med J Aust 2014;201:229-32.

46 Willmott $\mathrm{L}$, White $\mathrm{B}$, Parker M, et al. Is there a role for law in medical practice when withholding and withdrawing lifesustaining medical treatment? empirical findings on attitudes of doctors. J Law Med 2016;24:342-55. 